
31 THE EFFECT OF ADDING LIPIDS TO THE INTRAVENOUS FEEDING OF

P. Sauer, J. Van Aerde, J. 5 mith, D. Wesson, P. Swyer, P. Pencharz, Depts. Paed., Med. Eng. \& Surg., Univ. Toronto; Res. Inst., Hosp. Sick Children, Toronto, Canada. Sponsor HKA Visser. Previously we showed a decrease in metabolic rate in infants Previo Total Parenteral Nutrition (TPN) containing glucose + lipids receiving lotaly. In the present study we messured substrate
vs glucose only.
utilisation by. Indirect Calorimetry (IDC) over $5 \mathrm{hr}$ and from the utilisation by Indirect Calorimetry (IDC) over $5 \mathrm{hr}$ and frpm the
excretion of ${ }_{3} \mathrm{CO}_{2}$ during a primed constant infusion of $\mathrm{U}-\mathrm{I}_{\mathrm{C}} \mathrm{C}-\mathrm{glucose}$. Glucose oxidation (GO) was measured from the ${ }^{13} \mathrm{CO}_{2}$ enrichtment in breath at plateau and $f a t$ oxidation $(F D)$ as the difference of non-protein metabolic rate and glucose oxidation. We compared metabolic rate (MR) and substrate utilisation in two groups of AGA infants on an isocaloric intake. Group I received glucose/aminoacids only, Group II received a lipid emulsion as well, fat intake $2.0+0.1$ only, Group II received a 1 is emut $2.7+0.2 \mathrm{~kg})$, gest. oge $\left(35.9+1.0^{-}\right.$vs

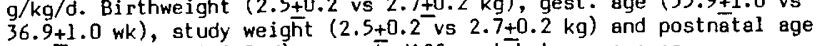
$(18.7 \pm 2.4$ vs $13.2 \pm 2.0$ d) was not different between groups.

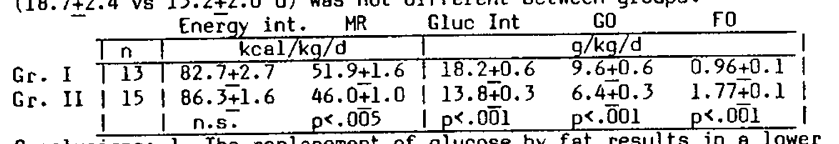
Conclusions: 1. The replacement of glucose by $f$ at results in $a$ lower metabolic rate, presumably as a result of a decreased conversion of glucose into fat. 2. Fat intake is almost equal to fat oxidation at
intake of $2 \mathrm{~g} / \mathrm{kg} / \mathrm{d}$. 3. ACA newborn infants oxidize fat efficiently. 4. TPN with $\mathrm{lipids}$ has advantages above glucose/amino acids only.

\section{CATCH UP GROWTH AND CHILD ABUSE}

J M King, L $S$ Taitz (Introduced by $R$ D G Milner) Department of Paediatrics, University of Sheffield, The Children.'s Hospital, Sheffield, England

Poor growth in association with child abuse is well recognised but eventual outcome in terms of growth parameters has not been clearly defined. The changes in standard deviation scores (SDS) for height and weight were calculated in 95 children who had suffered child abuse. Catch up growth was defined as an increase in SDS $>1.0$. Ages abuse. Catation ranged from 6 weeks to 12 years and length of follow up from 9 months to 8 years. The mean SDS for height and weight up from 9 months to 8 years. The mean SDS for height and weight
increased significantly between presentation and most recent clinic visit $(p<0.001$ and $p<0.01$ respectively). The 64 children who remained at home (group 1 ) showed a significant increase in height SDS only $(p<0.01)$. The 20 children taken into long term rostercare or adopted (group 2) showed significant increases in both height and weight SDS $(p<0.001$ and $p<0.01$ respectively). The remaining 11 children who were fostered for short periods only (group 3) showed little change in either index. Catch up growth in (group 3) showed little change in either index. Catch up growth in height occurred in $12 \%$ of group 1 compared to $55 \%$ group 2 ( 20.001. Catch up growth in weight occurred in $22 \%$ group 1 compared to $50 \%$
group $2(p<0.05)$. Children suffering child abuse show greater catch up growth when taken into long term care.
DECREASE OF PERIVENTRICULAR HEMORRHAGE WITHOUT PLANNED INTERVENTION A.G.S. Philip, L.R. Sawyer, W.C. Allan, Dept. of Pediatrics, Maine Medical Center, Portland, Maine. Intraventricular/periventricular hemorrhage (IV-PVH) continues to be a major problem for preterm infants. Since the advent of ultrasound scar ning, detection of IV-PVH has been made with some precision. We have routinely used an ATL sector scanner to detect IV-PVH in infants with gestational age $\ll 34$ weeks since 1979. All scans have been interpreted by a single individual (WCA), providing a high degree of consistency. During During the 5 year pertod Sept. 34 weeks gestation who of IV-PVH occurred, despite an sive decline in the overall incidence of IV-PVH occurred, despite a increase in the proportion of infants 26 weeks gestation. Oniy $2 \%$ (6\% of all IV-PVH) had evidence of parenchymal hemorrhage in 1981-84.

\begin{tabular}{|c|c|c|c|c|c|c|c|c|}
\hline \multirow{3}{*}{$\frac{\text { Year }}{1980}$} & \multirow{2}{*}{$\begin{array}{l}\text { Total } \\
<34 \mathrm{w} \\
\end{array}$} & \multirow{2}{*}{$\begin{array}{r}\mathrm{IV}-\mathrm{PVH} \\
<34 \mathrm{~W} \\
\end{array}$} & \multirow{2}{*}{$\begin{array}{l}\text { IV-PVH } \\
\leq 1500 \mathrm{~g} \\
\end{array}$} & \multirow{2}{*}{$\begin{array}{l}\text { Gest. } \\
\leqslant 26 \mathrm{~W}\end{array}$} & \multicolumn{4}{|c|}{ grade of IV-PVH (n) } \\
\hline & & & & & $\underline{\text { SEH* }^{*}}$ & IV & & $\underline{I P H}$ \\
\hline & 124 & $40 \%$ & $46 \%$ & $10 \%$ & 10 & $\overline{34}$ & $\overline{\langle 24 \%)}$ & 9 \\
\hline & 149 & $32 \%$ & $41 \%$ & $6 \%$ & 16 & 29 & $(19 \%)$ & $?$ \\
\hline & 119 & $29 \%$ & 33 & $13 \%$ & 1. & 22 & & 2 \\
\hline & 135 & $24 \%$ & $32 \%+$ & $13 \%$ & 11 & 20 & $(15 \%)+$ & 2 \\
\hline
\end{tabular}

*SE=sub-ependymal; 198 IP=intraparenchymal; $+=p<0.01$.

Using these data we have generated a grid to determine the risk of IVPVH according to birth-weight-gestational age categories.

Reasons for the decline in IV-PVH are uncertain, but include a decrease in outborn admissions and changing attitudes of obstetricians towards extren extre prolled trials in evaluating intervention. (See also Pediatr Res 19:1482-357a, 1985)
35 PERIVENTRICULAR LEUKOMALACIA OF THE PRETERM INFANT AND NEURODEVELOPMENTAL OUTCOME AT T8MON (Introduced by J.Micheli) Dept. Paed.CHUV, Lausanne, Switzerland Periventricular leukomalacia(PVL) can be accurately iden. tified in the neonatal period by means of ultrasonography and the use of high-frequency transducer. In order to establish its pronostic value, a prospective neurological and developmental assessment (Griffith's development quotient [DQ]) at 18 months corrected for prematurity was per formed on 82 infants of 34 weeks'gestation or less, alloca ted in 4 groups : 41 with normal scans(group I), 13 with isolated haemorrhage (group II), 4 with post-haemorrhagic ventricular dilatation(group III) and 24 with PVL associated or not with haemorrhage or dilatation(group IV). The outcome was good and similar in group I, II and III.

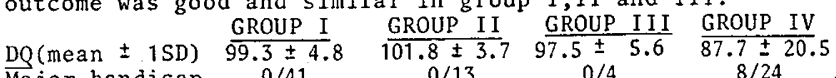

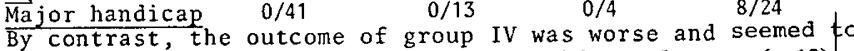
By contrast, the outcome of group IV was worse and seemed to all babies developed normally. 2) Frontal-parietal areas $(n=6): 3$ had major handicap. 3) Frontal-parietal-Occipital areas $(n=5)$ : all had major handicap. Our study indicate that major sequelae are more closely related to the extent and localisation of PVL than to haemorrhage or ventricular dilatation as previously reported. 33 DERANCDD ENEFGY METABOLISM IN THE BRAIN OF NEWBORN INFANIS WITH

PA Hanilton, PL Hope, BB Cady, AOM Cru, D Delpy, JS wyatt, EOR Reynolds Dept. of Paediatrics, University College London; London WCIE 6JJ, England.

Increased cerebral echodensities detected by ultrasound scarning of the brain in newtorn irfants of ten resolve, but sometimes progress to cystic periventricular leukoencephalopathy or other loss of brain tissue. The purpose of this investigation was to explore whether increased echodensities were assuciated with evidence of deranged cerebral energy metabol ism as determined by phosphorus nuclear magnetic deranged cerebral energy metabolini whether measurement of the energy status of cerebral tissue identified those infants who died or subsequently developed cysts or cerebral tissue

15 normal infants born between 28 and 40 weeks of gestation were studied as controls at ages between 1 day and 14 weeks, using methods that have previously been described ${ }^{1}$. The phuspho creatine $(\mathrm{PCr}) /$ inorganic orthophosphate $\left(\mathrm{P}_{\mathrm{i}}\right)$ ratio, which is an index of the energy state. of the tissue, increased fram $0.77 \pm 0.14195 \%$ confidence limits) at 30 weeks of gestational age plus postnatal age to $1.12 \pm 0.14$ at 40 weeks.

20 infants, bom at $29-41$ weeks of gestation, with increased echodensities (not apparently due to haemorrhage, and associated with birth asphyxia in 9 infants) were studied by MMPS aged 1day-tweeks. $\mathrm{PCr} / \mathrm{P}_{\mathrm{i}}$ was below the normal range in aill 5 infants who died. Sequential ultrasound scanning in the 15 survivors showed no evidence of loss of brain substance in the 5 infents hhose $\mathrm{PCr} / \mathrm{P}_{j}$ ratios were within the romkal range, whereas cysts or microcephaly developed in 8 of the 10 infants whose ratios were abnorrially low (Fisher's exact test, $\mathrm{p}<0.01$ ).

We conclude that (1) cenebral energy status was abnomal in sone infants with increased cerebral echodensities and (2), the infiants with abnumal energy status were much mure likely to die or show subsequent loss of brain substance.

1. Hope PL et al. Lancet 1984; ii: 336.

\section{OUTCOME OF PRETERM INFANTS WITH NEONATAL} Gillian Levitt, Alan Mushin, Susan Bellman and David Harvey. Queen Charlotte's Maternity Hospital, London United Kingdom.

The incidence of major disability associated with neonatal The incidence of major disab. The infants had been monitored for apnoea by routine nursing observations and intermittent $24 \mathrm{hr}$ pneumocardiograms. Thirty infants of less than 31 weeks gestation at birth were seen between 2 and 4 years of age. Full physical and ophthalmological examinations were carried out as well as audiometry and Griffiths

developmental assessment. The infants were divided into three groups according to the severity of the apnoea: Group I. no apnoea (15 infants); Group II, moderate apnoea I, no apnoea (15 infants); Group II, moderate apnoea (attacks of 20-59 seve apnoea (10 episodes in $24 \mathrm{hrs}$, an attack longer than 60 seconds or those requiring ventilation) (17 infants). The results of physical examinations were all normal. No overt defect of visual acuity was found but further fundal examination is being carried out. There was one case of sensorineural deafness in Group I. Developmental quotients (DQ) of the infants in the three groups showed there were no statistically significant differences: Group $I$, median DQ96; Group II, median DQ 102; Group III, median DQ 91 . The result of this study suggests that recurrent or severe apnoeic attacks do not imply a poor prognosis in infants with no other serious neonatal problems. 